\title{
Strategic Alliance Success Factors: A Literature Review on Alliance Lifecycle
}

\author{
Margherita Russo $^{1} \&$ Maurizio Cesarani ${ }^{1}$ \\ ${ }^{1}$ University of Milan-Bicocca, Milan, Italy \\ Correspondence: Maurizio Cesarani, University of Milan-Bicocca, Milan, Italy.
}

Received: March 9, 2017

Accepted: March 28, 2017

Online Published: May 3, 2017

doi:10.5430/ijba.v8n3p1

URL: https://doi.org/10.5430/ijba.v8n3p1

\begin{abstract}
Objectives. The research aims to investigate how firms can achieve alliance success. In global markets, the alliance failure rate is very high. This study will try to understand why, facing with such a high failure rate, more and more firms decide to enter or form strategic alliances. It appears necessary to identify key factors and show how firms can successfully manage them in each phase of alliance lifecycle.

Methodology. For this study, a qualitative approach was adopted, in order to explore and understand the research problem. The issues of alliance success factors is investigated through the analysis of the existing literature, focusing in particular on the last two decades.

Findings. By reviewing several theoretical perspectives, we identified alliance success factors and showed what kind of relevance they have in each phase of alliance lifecycle. It was found that strategic alliances develop through three phases. Alliance success lies on successful management of key factors, involved in each phase.

Research Limits. Research deals with the issues of alliance success factors at the level of a single alliance and not at the level of an alliance portfolio. Further research should extend the analysis perspective.

Managerial Implications. Firms involved in a strategic alliance should consider several critical aspects. For the entire alliance lifecycle, they have to look for a high degree of fit with their own partners. Another important aspect is related to the risk of opportunistic behavior, which could be reduced through the choice of an appropriate governance form and the development of social capital.
\end{abstract}

Keywords: strategic alliance, global markets, alliance success, global networks, competitive advantage, alliance failure

\section{Introduction}

Over the past decades, the importance of strategic alliances has substantially increased and they have been seen as a response to the challenges of market globalization. Alliances play a critical role in firm survival, providing the access to critical resources that allow gaining and maintaining competitive advantages in today turbulent economic environment (Cobeña et. al., 2017). They become a trend in global markets; more and more firms adopt cooperative strategies because the external market conditions show a lack of internal resources that they need for preserving their own competitive position in the marketplace. Competition is no more between individual firms but between alliance networks (Brondoni, 2010). Collaborative agreements allow firms to bridge internal weaknesses and cope the complexity of business environment. Companies, in order to strengthen their resources' endowment, enhance their competitiveness and manage environmental uncertainty, increasingly depend on external partners. For firms, strategic alliances represent an important instrument to ensure the knowledge advancement and the availability of complementary resources (Lubello et al., 2015). Companies can set cooperative strategies with a wide range of solutions of equity and non-equity alliances (Brondoni, 2003). A strategic alliance is an intentional relationship between two or more firms, which remain legally independent, involving exchange, sharing or co-development of resources, competences and capabilities (Gulati, 1995). A strategic alliance is an important source of growth and competitive advantages (Ireland et. al., 2002; Kale \& Singh, 2009) thanks to its own benefits that have been highlighted as follows (Arrigo, 2012): transaction costs, the enhancement of the competitive position and the acquisition of knowledge. Firms involved in a strategic alliance could create value through several sources: scale 
economies, effective risk management, cost efficient market entries and, especially, learning from partners (Arrigo, 2012; Ireland et al., 2002).

Although the strategic importance of alliances, they still exhibit a very low success rate; previous research showed a failure rate at or over 50\% (Lorange \& Ross, 1992; Bleeke \& Ernst, 1993; Faulkner, 1995; Bamford et al., 2004; Lunnan \& Haugland, 2008; Kale \& Singh, 2009; Madhok et al., 2015; Linwei et al., 2017). The high failure rate highlights the difficulties of building successful alliances and the fact that not all firms have the abilities to maximize the potential value creation from their cooperative strategies. The reasons behind the high failure rate are mainly related to the lack of familiarity that firms have with the dynamic nature of the collaborative relationships, which are characterized by the simultaneous presence of competition and cooperation. Cooperation refers to the sharing of a common project; instead, competition concerns the achievement of personal objectives. Therefore, strategic alliances could lead to competitive or cooperative behaviors, depending on the private incentives of the partners (Parkhe, 1993). When excessive competition eclipses cooperative orientation, the strategic alliance reveals a failure and a value destruction for firms involved. On such assumptions, inter-firm competition and managerial complexity have been identified as the main reasons of alliance failure (Park \& Ungson, 2001). The first one refers to the risk of partner's opportunistic behavior that can undermine the spirit of collaboration (Varma et al., 2015); instead, the second one refers to potential conflicts due to lack of cultural, strategic and structural fit among partners. In today global markets on one hand, the number of alliances continue to grow and on the other hand, their success rate is still very low. It seems that that while most firms have realized the importance of strategic alliances only few of them have understood how to manage them successly (Saebi, 2011; Duysters et al., 2011). The main purpose of this work is to identify the way firms can address the high risk of failure, investigating the main factors that lead strategic alliances toward success. The research aims to understand why, facing with such a high failure rate, more and more firms decide to enter or form strategic alliances. It appears therefore necessary to identify key factors and show how firms can successfully manage them in each phase of the alliance lifecycle.

\section{Literature Review}

\subsection{Transaction Cost Theory}

Transaction cost theory (Coase, 1937; Williamson, 1981) shows how firms choose the most appropriate governance structure. The theory states that transaction costs are due to bounded rationality, opportunistic behavior and assets specificity. Bounded rationality, caused by complexity and environmental uncertainty, is the impossibility to foresee all possible situations that may arise and their outcome (Cesarani, 2014). Williamson (1981) defines opportunistic behavior as "self- interest seeking with guile"; it means that partner pursues personal goals at the expense of the collective ones. Assets specificity are investments made for supporting a particular transaction, which do not create value outside of it. In the field of strategic alliance, they are termed as "investment in partner-specific". According to Transaction cost theory, when firms choose the mode of transactions, they are moved by the aim to reduce costs. Williamson (1981) states that firms minimize costs when the governance form matches exchange conditions. In the logic of Transaction cost, strategic alliances are an intermediate or hybrid organizational forms, located in the middle, between market and hierarchy. They are the most appropriate governance form to govern relationships that are not very complex as to require the use of hierarchy, but more complex than those entrusted to the market Alliances allow firms to decrease the amount of production and transaction costs because it is expected that partners behave cooperatively toward common goals. However, strategic alliances are not exempt from the risk of partner's opportunistic behaviors. In order to reduce such risk, Transaction cost supports the choice of equity joint venture because ownership aspect tends to limit the risk of opportunism. Equity alliances create a situation of "mutual hostage"; in fact, sharing equity fosters the alignment of partner's objectives. Finally, Transaction Cost Theory identifies "the choice of an appropriate governance structure" as a key factor for alliance success.

\subsection{Knowledge Based View \& Social Exchange Theory}

Knowledge based view (Grant, 1996; Spender, 1996) states that firms, in choosing alliance strategies, are moved by the aim to "learning". Through cooperative agreements, firms can enhance their knowledge base. According to Kale $\&$ Singh (2007) firms, from prior experience, learn more about alliance management and develop alliance know-how that could be used in future alliances. Strategic alliances become a popular vehicle for organization learning and knowledge sharing (Jiang et al., 2016). Although strategic alliances offer opportunities for knowledge sharing, they also carry the risk of knowledge leakage to partner (Jiang et al., 2016). Firms have to consider also negative aspects, involved in knowledge sharing, such as the risk of core competences appropriation or a learning race. In order to prevent this kind of risks, it is necessary to develop "relational capital" among partners; it acts as a safeguard against the risk of opportunistic behavior. Such assumption introduces the next theoretical perspective: Social exchange 
theory (Blau, 1964); it supports the logic of "relational based governance", highlighting the importance of developing social capital for reducing the threat of partner's opportunistic behavior (Gulati, 1995). The theory identifies relational factors such as mutual trust and mutual commitment as forms of relational safeguard. Mutual commitment is a sense of duty toward the partner; it creates a sense of loyalty and cooperation and provides a basis for communication between partners (Muthusamy \& White, 2005). Trust is as reliance on another part under conditions of risk. The combination of these two relational factors creates a sense of loyalty and cooperation among partners and reduce the risk of opportunistic behavior (Gulati, 1995). The development of social capital has positive effects on alliance relationship; it enhances openness and accessibility, increases the scope of the relationship and mutual knowledge learning (Kale \& Singh, 2009). In a strategic alliance, high degrees of trust and commitment foster not only the mutual learning but also the development of new skills and competencies. Finally, Knowledge based view and Social exchange theory identify the "development of social capital" as a key factor for alliance success.

\subsection{Resource Based Theory}

The Resource based theory (Barney, 1991; Peteraf, 1993) highlights the critical role played by resources. Strategic alliances are considered as a mean to access to unavailable resources and develop jointly new ones. Firms are bundles of resources and their competitive position is defined by their own resources endowment. Markets are often incomplete and imperfect and therefore it is not easy for firms to acquire the needed resources. Such resources, indeed, may be not perfectly tradable or even not tradable at all. Therefore, companies decide to form or enter into a strategic alliance for filling their gap of resources. They share resources with partners and identify the most optimal configuration that maximizes the value of such resources. Resource based view identifies complementary resources as s key factor for alliance success. Lambe et al. (2002) define complementary resources as the degree in which firms can cover each other's lack of resources defines them. High similarity among resources allows firms to gain economies of scale and exploit the existent competitive advantages; different but complementary resources allow gaining economies of scope, synergies, developing new resources and subsequently achieving new forms of competitive advantage (Ireland et al., 2002). The combination of complementary resources leads the development of "idiosyncratic resources" (Lambe et al., 2002). They are valuable resources, developed during the alliance lifecycle (Jap, 1999). These resources have little value outside the alliance relationship and allow firms to achieve a strong competitive advantage when they are combined in a way that competitors cannot easily replicate. Finally, Resource based view identifies the "crucial role of complementary and idiosyncratic resources" as key factor for alliance success.

\subsection{Dynamic Capability and Alliance Capability View}

Dynamic Capabilities view (Teece et al., 1994) has been largely used to explain the conditions of alliance success. The theory is considered as an extension of the Resource based view; in fact, it states that under unpredictable market conditions, resources endowment is no more sufficient to justify the heterogeneity in firms' performance (Saebi, 2011). Dynamic capabilities view emphasizes the reconfiguration of such resources (Helfat and Peteraf, 2003). Firms that operate in a dynamic environment have to identify the best way of integrating, renewing, reconfiguring and recreating their bundle of resources. Companies, in order to strengthen their competitiveness, need to develop a high order of resources that enhance the productivity of the basic ones. Dynamic capabilities are defined as organizational routines that affect change in the firm's existing resource base (Eisenhardt and Martin, 2000). They are heterogeneously distributed among firms and therefore represent a source of competitive advantage. As stated by Saebi (2011), Dynamic capability view has an important implication on alliance literature; it promotes a shift in research focus from relational or structural factors, peculiar to the individual alliance relationship, towards managerial capabilities specific of a single firm. According to such assumption, alliance success lies not only in the relationship between partners, but also in each firm's alliance management capabilities (Duyster et al., 2011). The concept of alliance capabilities derives from the assumptions of Dynamic capabilities view. Alliance management capabilities are a kind of dynamic capabilities, defined as superior firm's capabilities in managing alliances (Heimeriks \& Schreiner, 2010). They are heterogeneously distributed across firms and for this reason are useful to justify performance difference among firms. Lambe (2002) states that alliances are successful if firms develop the capabilities needed for managing them. Finally, Dynamic capability and Alliance capabilities view identify "alliance management capabilities" as key factor for alliance success.

\subsection{Literature Review Summary}

Figure 1 summarizes the result of the literature review. Each theoretical perspective identifies a potential reason for alliance formation and a critical factor for alliance success. However, each single theory is not sufficient on its own 
to explain the complexity of the issue. For this reason, a combination of all the identified theories is required and useful to provide a clear understanding of the alliance success phenomenon in global markets. For example, on the one hand, transaction cost theory identifies the choice of the appropriate governance structure as a success factor, considering the risk of opportunistic behavior, but gives no solutions on how to prevent and manage it. On the other hand, the social exchange theory provides the developing of relational capital as a safeguard against the opportunistic behavior, integrating in this way the previous theory. Similarly, on the one hand, the resource based view looks at strategic alliances as the mean to identify the optimal resources combination for their value maximization, but it does not consider that market competitive conditions are not static and may change. On the other hand, dynamic capability view faces the evolution of the market, where resources' endowment is not sufficient to obtain success from a strategic alliance. In fact, this theory supports the importance of resources reconfiguration and looks at strategic alliances as the mean to create a higher order of resources.

\begin{tabular}{|c|c|c|}
\hline Theoretical Perspective & Reasons & Success Factors \\
\hline Transaction Cost Theory & $\begin{array}{l}\text { Reducing the sum of transaction } \\
\text { and production costs }\end{array}$ & $\begin{array}{l}\text { Choice of the appropriate governance } \\
\text { structure that limits the threat of } \\
\text { partner's opportunistic behavior }\end{array}$ \\
\hline $\begin{array}{l}\text { Knowledge Based View \& } \\
\text { Social Exchange Theory }\end{array}$ & $\begin{array}{l}\text { Knowledge sharing: Knowledge } \\
\text { acquisition \& Knowledge access }\end{array}$ & $\begin{array}{l}\text { Alliance know-how on alliance } \\
\text { management, gained from prior } \\
\text { alliance experience. } \\
\text { Developing of "relational capital" such } \\
\text { as trust, mutual commitment and } \\
\text { power- sharing }\end{array}$ \\
\hline Resource Based View & $\begin{array}{c}\text { Potential value creation of partners' } \\
\text { resources, which are pooled } \\
\text { together. Partner firms } \\
\text { opportunities to access unviable } \\
\text { resources and to develop jointly } \\
\text { new resources }\end{array}$ & $\begin{array}{c}\text { Partner's complementary resources and } \\
\text { development of idiosyncratic ones, } \\
\text { during the alliance lifecycle }\end{array}$ \\
\hline $\begin{array}{l}\text { Dynamic Capability View \& } \\
\text { Alliance Management } \\
\text { Capability View }\end{array}$ & $\begin{array}{l}\text { Reconfiguration of the existing } \\
\text { resources. Identification of the best } \\
\text { way ,through which partner firms } \\
\text { can integrate, renew and } \\
\text { reconfigure the bundle of their base } \\
\text { resources. }\end{array}$ & $\begin{array}{l}\text { Partner firms organizational and } \\
\text { managerial capabilities, which are } \\
\text { termed "Alliance management } \\
\text { capabilities". } \\
\text { Importance of developing "Alliance } \\
\text { management capabilities" as a } \\
\text { high-order of resources in managing } \\
\text { alliance relationship }\end{array}$ \\
\hline
\end{tabular}

Figure 1. Summary framework on alliance rationales and alliance success factors

\section{Methodology}

The research aims to investigate how firms can achieve successful alliances. In global markets, the alliance failure rate is very high. This study tries to understand why, facing with such a high failure rate, more and more firms decide to enter or form strategic alliances. In order to accomplish this goal, a qualitative approach was adopted. This kind of method is more appropriate when the purpose involves exploration and understanding of the research problem. Indeed, qualitative methodologies reflect the reality but they might overlook results and concerns raised in previous theoretical works. However, our research aligns with the idea that the consideration of the existent body of literature is central for the qualitative study design. The approach to the research problem is therefore descriptive-explorative, 
given the great amount of literature about the topic on the one hand and a lack of a clear and unique overview on the other hand.

The issue of alliance success factors is investigated through the analysis of the existing literature. In particular, we focused on the most important and cited theories that represent the theoretical background of the issue. The emerging theories are: Transaction cost theory; Knowledge based view; Social exchange theory; Resource based view; Dynamic capabilities view; and Alliance management capabilities view. Through the review of such theoretical views, we identified reasons that lead firms to choose collaborative strategies and critical factors that make the choice to ally a winning choice. Each theory has been useful to clarify a success factors during alliance lifecycle. The key factors identified are: the choice of the appropriated alliance governance form; the development of social capital; complementary resources; alliance management capabilities. Those success factors have been applied to a specific phase of alliance lifecycle, in which they have a specific relevance. In fact, strategic alliances are composed by steps, through which the alliance relationship emerges, grows and dissolves. The development of a strategic alliance is termed "alliance lifecycle", because alliance is similar to an entity that grows, develops and dies in nature. The lifecycle of an alliance is composed by a set of different collaboration phases, ranging from alliance formation to alliance termination. Based on the existent literature on alliance development (Lorange \& Ross, 1993; Murray \& Mahon, 1993; Ring \& Van de Ven, 1994; Faulkner, 1995: Dussage \& Garrette, 1998; Spekamn et al., 1998; Kale \& Singh, 2009) we divided the alliance lifecycle in three main phases: Formation, Operational and Evaluation Phase. Each phase has important effects on the others; in fact, alliance proceeds to the next step only if the objectives of the previous one have been achieved. The overall success lies in identifying and managing successfully the key factors that characterize each phase of the alliance lifecycle.

\section{Findings}

\subsection{Alliance Formation Phase}

Alliance formation phase is the initial phase in which firms manifest an interest in forming a strategic alliance; they analyze reasons and potential alliance benefits, select partners and choose the most appropriate form of cooperation for alliance management. In this phase, there are two key factors: partner selection and choice of the most appropriate governance form for alliance management.

Partner selection is very crucial for alliance success. Das \& Teng (2003) states that choosing the right partners means finding desirable matches between partners' resources, goals and strategies. From the beginning and for the overall alliance lifecycle, firms have to look for a certain degree of fit between partners. Alliance success depends on a high level of fit among partners. Lack of fit could lead the alliance toward failure. Firms involved in partner selection activity have to consider three fundamental criteria: partner complementarity, congruence and compatibility. Partner complementarity refers to the concept of strategic fit. Strategic fit is higher when the alignment of complementary resources is useful to bridge the gap of each partner; in fact, complementary resources play a critical role for alliance success. Partner congruence refers to partners' goals and objectives alignment. In order to achieve success, partners have to define clear and compatible goals. Partner's objective could be different but they have to be compatible. Goals that cannot be achieved simultaneously lead alliance toward failure. Partner compatibility refers to partners' cultural and organizational fit. Cultural fit means that the partner is sensible toward different cultures and willing to find integration between the elements of distance (Child et al., 2005). Cultural resistance creates conflicts that could jeopardize the alliance success. Organizational fit means that partners are willing to adapt to each other's management practices, organizational culture, procedures, and working (Park \& Ungson, 1997). Lack of organizational fit could arise conflicts and coordination problems and lead toward alliance failure.

The choice of the most appropriate governance form for alliance management is the second key activity of the formation phase. It allows reducing the risk of opportunistic behavior. Firms can choose between different forms: equity ownership, contractual provisions and self-enforcing governance. (Kale \& Singh, 2009). The equity ownership is preferred when the risk of opportunistic behavior and environment uncertainty are very high. Contractual provisions are useful to clarify mutual rights and duties, partners' contributions, the way through which exchanges take place and potential conflicts are solved (Kale \& Singh, 2009). Self- enforcing governance is a "relational based governance"; it stress, as stated by Social exchange theory, the importance of developing relational factors for alliance success.

\subsection{Alliance Operational Phase}

The operational phase is the phase in which alliance vision is translated in economic reality; it is called by Das \& Teng (2003) as crossroads, because partner interactions are very high and the risk of conflicts increases. Partners work on a daily base and they have to take important decisions related to coordination and monitoring of alliance 
activities, management of communication and learning process. This is a very critical phase in which many alliances fail. Success factors, involved in this phase, are coordination, trust and commitment, control, communication and conflicts.

Coordination is an essential factor in alliance relationship development for managing the interdependence (Varma et al., 2015). Mohr \& Spekman (1994) defines coordination as a set of tasks that each partner expects the other to perform in order to reach the common objectives. High level of coordination allows companies to achieve stability in alliance relationships. Coordination lapses such as unclear roles, procedures and responsibilities lead to alliance failure; in fact, firms have to developed and appropriate framework for their ongoing interactions, composed by rules, policies and procedures that guide cooperation (Varma et al., 2015).

Trust and Commitment represent the soft side of alliance management. The development of social capital enhances alliance success likelihood; it supports and fosters an effective alliance operation day-to-day, allows firms to increase productivity, lower costs and promote a sense of belonging among partners (Varma et al., 2015). Without feelings of trust and commitment, partners could act opportunistically such as they could hold back important information or could gain unfair advantages on the others (Gulati, 1995). The combination of these two relational factors helps firm to reduce the risk of opportunistic behavior, it leads partners to work together towards common objectives (Yang et al., 2011).

Control is a set of rules and mechanisms that allows to make partners' behavior more predictable and to bond their actions to cooperation intents. It is necessary, for alliance success, that firms establish an appropriate level of control, which allows partners to balance collaborative aspects with the competitive one. Inadequate level of control may limit the protection and the efficient utilization of valuable resources. On the other hand, an excessive control on alliance activities could destroy goodwill and benevolence among partners, which will have limited autonomy to perform their job (Child et al., 2005). Establishing an appropriate level of control, through formal control mechanisms such as protocols and periodic checks, enhances cooperation and helps to solve potential conflicts and problems in real time (Sklavounos et al., 2015).

Communication is a very critical factor for alliance success; it collects information about the trustworthiness of each partner, helps to manage potential conflicts, integrates potential differences and promotes coordination between different levels of hierarchy. In order to enhance alliance success likelihood, it is necessary that information sharing among partners is timely and open and that feedbacks are credible and accurate. Alliance success depends on how partners manage the information flows. Regular sharing of information about day- to day-managerial operation promotes coordination and promotes the development of mutual commitment toward the achievement of common goals (Spralls et al., 2011). According to Neisten \& Jolink, (2015) open communication promotes a better and mutual understanding among partners regarding rules, obligations and develop shared model to work together. Partners with a shared vision will be more committed to the alliance (Spralls et al., 2011).

Conflicts often exist in alliance relationship due to the high level of interdependence among partners; the success factor lies in the way they are managed and solved. Managing conflicts is a critical challenge for alliance management (Das \& Teng, 2003). The main sources of alliance conflicts are due to organizational, managerial and cultural differences among partners. Khanna et al. (1998) identified another source of alliance conflicts in asymmetrical partners 'contributions and returns; fundamental conditions for alliance success is creating a win- win situation. Perception of equity leads partners to remain committed for all the duration of the alliance. In addition, a different set of alliance's expectations could lead to conflicts; partners could have different objectives, but it is important that these objectives are compatible and that they can be achieved simultaneously.

\subsection{Alliance Evaluation Phase}

The evaluation phase represents the moment of the alliance lifecycle in which it matures and realizes its potential benefits. Alliance performance evaluation and further alliance development are the two key elements involved in this phase. They are closely intertwined; partners, through the performance assessment, decide the further alliance development (Tjemkes et al., 2013).

Alliance performance evaluation is a very critical factor because it shows the progress during the alliance lifecycle. Previous literature looked at alliance performance as the extent to which alliance objectives are reached. Performance evaluation allows partners to understand if an alliance requires adaptations or termination (Tjemkes et al., 2013). Partners have to develop an integrated performance evaluation approach, composed by metrics that assess all the multiple aspects of strategic alliances performance. There are many different kinds of performance and their combination provides an integrated and coherent performance evaluation outcome. Each kind of performance provides important information about a particular aspect of alliance development (Tjemkes et al., 2013). Economic 
performance evaluates the economic value of the alliance relationship; it allows partners to assess whether the alliance is useful to increase their value. Strategic performance evaluates the alliance management effectiveness; it provides important information for stakeholders, top management and alliance managers and shows how critical factors have to be managed for achieving a superior alliance performance. Operational performance assesses efficiency and effectiveness of alliance process on a daily base. Learning performance provides important information about the outcome of leaning process. Relational performance assesses the value of interpersonal relationship. Measuring the status of alliance relationships is a key activity, because valuable relationships among partners enhance alliance success likelihood. An appropriate alliance evaluation, based on such different kind of alliance performance, provides a comprehensive understanding of alliance status and supports the partners in decision making about the further development of the relationship.

Further alliance development shows how the alliance evolves over time; it includes several development options leading to re-organization or termination. The options of further alliance development are natural end, extension, premature termination, changes in the alliance structure and takeover of one partner by the other (Tjemkes et al., 2013). Alliance natural end is the situation in which alliance comes to a natural end because the goals have been met Alliance is extended or expanded when partners decide to prolong their collaboration or expand it to new joint projects. Premature termination means that the alliance ends before the objectives have been reached. Partners could decide to terminate the alliance if it generates insufficient value or when they perceive an unfair value sharing related to their contribution. Changes in alliance structure means changing alliance governance forms such as when a firm decides to take an equity share in its partner, turning non-equity into equity alliance. Takeover of one partner by the other is the situation in which a partner internalize alliance activities and acquire all the control. The strategic alliance ends because one partner acquires the other.

\section{Conclusions}

Over the past two decades, strategic alliances has become an important source of growth and competitive advantage. Firms engage in a large number of cooperative agreements, in order to strengthen their competitive position, enter new markets and access critical resources and capabilities. Although the strategic importance of alliances, they still exhibit a very low success rate. The research contributes, through the literature review of important theoretical perspectives, to identify several critical factors and show how firms have to manage them successfully for the entire alliance lifecycle. The development and management of alliance success factors increase the overall alliance success. However, this study is subject to limitations. First, the research is mainly based on theoretical assumptions; further researches should test its validity through an empirical analysis. Second, the research deals with the issues of alliance success factors at the level of a single alliance and not at the level of an alliance portfolio.

Further research should shift the focus from a dyadic to a portfolio level, attempting to uncover the issues that emerge from the management of multiple simultaneous alliances with different partners. In fact, in order to respond to the increasing globalization of markets, firms often operate and compete through global networks. It should be interesting to investigate firms' challenges in managing a complex alliance portfolio.

The study has some managerial implications about the decisions and actions to take during the alliance lifecycle. In fact, when a firm decides to enter or form a strategic alliance, it should take into account several critical aspects. During formation phase, as well as for the entire alliance lifecycle, firms have to look for and maintain a high degree of fit with their own partners together with the choice of the most suitable alliance governance form. Alliances often fail because inexperienced firms pay more attention on their own objectives, instead of conducting a detailed due diligence in partner selection. During operational phase, firms should focus on the development of relational factors such as coordination, communication, trust and commitment, and conflicts resolution. A set of these factors represents the alliance social capital, which leads to high levels of cooperation, fosters information sharing, reduces relational risk and promotes open communication among partners, increasing the overall alliance success likelihood. Finally, during evaluation phase, alliance performance evaluation is required, through many points of view: economic, strategic, operational, learning, and relational. The combination of such aspects provides a comprehensive and integrated evaluation of the alliance relationship and gives guidelines for further developments.

Finally, forming a strategic alliance requires a high effort to coordinate and integrate two or more independent firms, and the effort is even greater when they come from different national, cultural, political, managerial and economic backgrounds. It means that partners have to understand differences and being willing to find a compromise when differences lead to conflicts. In the context of global markets, differences could be very high and may hinder the process of building and managing the strategic relationship; if not properly handled may constitute cause of alliance failure. 


\section{References}

Arrigo, E. (2012). Alliances, Open Innovation and Outside-in Management. Symphonya. Emerging Issues in Management (symphonya.unimib.it), 2, 53-65. http://dx.doi.org/10.4468/2012.2.05arrigo

Bamford, J., Ernst, D., \& Fubini, D. G. (2004). Launching a world-class joint venture. Harvard Business Review, 82(2), 90-100.

Barney, J. (1991). Firm resources and sustained competitive advantage. Journal of Management, 17(1), 99-120. https://doi.org/10.1177/014920639101700108

Blau, P. M. (1964). Exchange and power in social life. New York: Wiley. https://doi.org/10.2307/2574842

Bleeke, J., \& Ernst, D. (Eds.). (1993). Collaborating to Compete: Using Strategic Alliances and Acquisitions in the Global Marketplace. New York: John Wiley. https://doi.org/10.1016/0022-5428(93)90023-i

Brondoni, S. M. (2003). Network Culture, Performance \& Corporate Responsibility. Symphonya. Emerging Issues in Management (symphonya.unimib.it), 1, 8-24. https://doi.org/10.4468/2003.1.02brondoni

Brondoni, S. M. (2010). Intangibles, Global Networks \& Corporate Social Responsibility. Symphonya. Emerging Issues in Management (symphonya.unimib.it), 2, 6-24. https://doi.org/10.4468/2010.2.02brondoni

Cesarani, M. (2014). Competitive Dimension of Outsourcing Relations in Global Networks. Journal of Management Policies and Practices, 2(4), 97-112. https://doi.org/10.15640/jmpp.v2n4a5

Child, J., Faulkner, D., \& Tallman, S. B. (2005). Cooperative strategy. Oxford, MS: Oxford University Press. https://doi.org/10.1093/acprof:oso/9780199266241.001.0001

Coase, R. H. (1937). The nature of the firm. Economica, 4(16), 386-405. https://doi.org/10.2307/2626876

Cobeña, M., Gallego, Á., \& Casanueva, C. (2017). Heterogeneity, diversity and complementarity in alliance portfolios. European Management Journal. https://doi.org/10.1016/j.emj.2016.12.005

Das, T. K., \& Teng, B. S. (2003). Partner analysis and alliance performance. Scandinavian journal of management, 19(3), 279-308. https://doi.org/10.1016/s0956-5221(03)00003-4

Duysters, G., Saebi, T., \& De Man, A. P. (2011). Shaping the alliance management agenda: a capability approach. Journal on Chain and Network Science, 11(3), 191-196. https://doi.org/10.3920/jcns2011.x205

Eisenhardt, K. M., \& Martin, J. A. (2000). Dynamic capabilities: what are they?. Strategic Management Journal, 1105-1121. https://doi.org/10.1002/1097-0266(200010/11)21:10/11\%3C1105::aid-smj133\%3E3.0.co;2-e

Faulkner, D. (1995). International strategic alliances: Co-operating to compete. Maidenhead: McGraw-Hill. https://doi.org/10.1016/0024-6301(95)90242-2

Grant, R. M. (1996). Toward a knowledge-based theory of the firm. Strategic Management Journal, 17(S2), 109-122. https://doi.org/10.1002/smj.4250171110

Gulati, R. (1995). Does familiarity breed trust? The implications of repeated ties for contractual choice in alliances. Academy of Management Journal, 38(1), 85-112. https://doi.org/10.2307/256729

Heimeriks, K. H., \& Schreiner, M. (2010). Relational quality, alliance capability, and alliance performance: An integrated framework. In Enhancing Competences for Competitive Advantage (pp. 145-171). Emerald Group Publishing Limited. https://doi.org/10.1108/s0749-6826(2010)0000012009

Helfat, C. E., \& Peteraf, M. A. (2003). The dynamic resource-based view: Capability lifecycles. Strategic Management Journal, 24(10), 997-1010. https://doi.org/10.1002/smj.332

Ireland, R. D., Hitt, M. A., \& Vaidyanath, D. (2002). Alliance management as a source of competitive advantage. Journal of Management, 28(3), 413-446. https://doi.org/10.1177/014920630202800308

Jiang, X., Bao, Y., Xie, Y., \& Gao, S. (2016). Partner trustworthiness, knowledge flow in strategic alliances, and firm competitiveness: A contingency perspective. Journal of Business Research, 69(2), 804-814. https://doi.org/10.1016/j.jbusres.2015.07.009

Kale, P., \& Singh, H. (2007). Building firm capabilities through learning: the role of the alliance learning process in alliance capability and firm-level alliance success. Strategic Management Journal, 28(10), 981-1000. https://doi.org/10.1002/smj.616

Kale, P., \& Singh, H. (2009). Managing strategic alliances: What do we know now, and where do we go from here. Academy of Management Perspectives, 23(3), 45-62. https://doi.org/10.5465/amp.2009.43479263 
Lambe, C. J., Spekman, R. E., \& Hunt, S. D. (2002). Alliance competence, resources, and alliance success: conceptualization, measurement, and initial test. Journal of the Academy of Marketing Science, 30(2), 141-158. https://doi.org/10.1177/03079459994399

Linwei, L., Feifei, J., Yunlong, P., \& Nengqian J. (2017). Entrepreneurial orientation and strategic alliance success: The contingency role of relational factors. Journal of Business Research, 72, 46-56. https://doi.org/10.1016/j.jbusres.2016.11.011

Lubello, N., Albano, M., \& Gordini, N. (2015). Il ruolo delle PMI nei processi di Open Innovation. 4th Workshop - I Processi Innovativi nelle Piccole Imprese: Re-positioning of SMEs in the Global Value System, Urbino. https://doi.org/10.13140/RG.2.1.3951.4645

Lunnan, R., \& Haugland, S. A. (2008). Predicting and measuring alliance performance: A multidimensional analysis. Strategic Management Journal, 29(5), 545-556. https://doi.org/10.1002/smj.660

Madhok, A., Keyhani, M., \& Bossink, B. (2015). Understanding alliance: Adjustment costs and the economics of resource value. Strategic Organization, 13(2), 91-116. https://doi.org/10.1177/1476127015580309

Mohr, J., \& Spekman, R. (1994). Characteristics of partnership success: partnership attributes, communication behavior, and conflict resolution techniques. Strategic Management Journal, 15(2), 135-152. https://doi.org/10.1002/smj.4250150205

Muthusamy, S. K., \& White, M. A. (2005). Learning and knowledge transfer in strategic alliances: a social exchange view. Organization Studies, 26(3), 415-441. https://doi.org/10.1177/0170840605050874

Niesten, E., \& Jolink, A. (2015). The impact of alliance management capabilities on alliance attributes and performance: a literature review. International Journal of Management Reviews, 17(1), 69-100. https://doi.org/10.1111/ijmr.12037

Park, S. H., \& Ungson, G. R. (1997). The effect of national culture, organizational complementarity, and economic motivation on joint venture dissolution. Academy of Management Journal, 40(2), 279-307. https://doi.org/10.2307/256884

Parkhe, A. (1993). Strategic alliance structuring: A game theoretic and transaction cost examination of interfirm cooperation. Academy of Management Journal, 36(4), 794-829. https://doi.org/10.2307/256759

Peteraf, M. A. (1993). The cornerstones of competitive advantage: A resource-based view. Strategic Management Journal, 14(3), 179-191. https://doi.org/10.1002/smj.4250140303

Saebi, T. (2011). Succesfully managing alliance portfolios: An alliance capability view. Doctoral dissertation: Maastricht University.

Sklavounos, N. S., Rotsios, K. P., \& Hajidimitriou, Y. A. (2015). The impact of age, interdependence and perceived risk of opportunism on inter-partner trust in international strategic alliances. Procedia Economics and Finance, 19, 175-183. https://doi.org/10.1016/s2212-5671(15)00019-2

Spender, J. C. (1996). Making knowledge the basis of a dynamic theory of the firm. Strategic Management Journal, 17(S2), 45-62. https://doi.org/10.1002/smj.4250171106

Spralls, S. A., Hunt, S. D., \& Wilcox, J. B. (2011). Extranet use and building relationship capital in interfirm distribution networks: The role of extranet capability. Journal of Retailing, 87(1), 59-74. https://doi.org/10.1016/j.jretai.2010.09.001

Teece, D., \& Pisano, G. (1994). The dynamic capabilities of firms: an introduction. Industrial and Corporate Change, 3(3), 537-556. https://doi.org/10.1093/icc/3.3.537-a

Tjemkes, B., Vos, P., \& Burgers, K. (2013). Strategic alliance management. London: Routledge.

Varma, S., Awasthy, R., Narain, K., \& Nayyar, R. (2015). Cultural determinants of alliance management capability an analysis of Japanese MNCs in India. Asia Pacific Business Review, 21(3), 424-448. https://doi.org/10.1080/13602381.2015.1022332

Williamson, O. E. (1981). The economics of organization: The transaction cost approach. American Journal of Sociology, 87(3), 548-577. https://doi.org/10.1086/227496

Yang, H., Lin, Z. J., \& Peng, M. W. (2011). Behind acquisitions of alliance partners: exploratory learning and network embeddedness. Academy of Management Journal, 54(5), 1069-1080. https://doi.org/10.5465/amj.2007.0767 